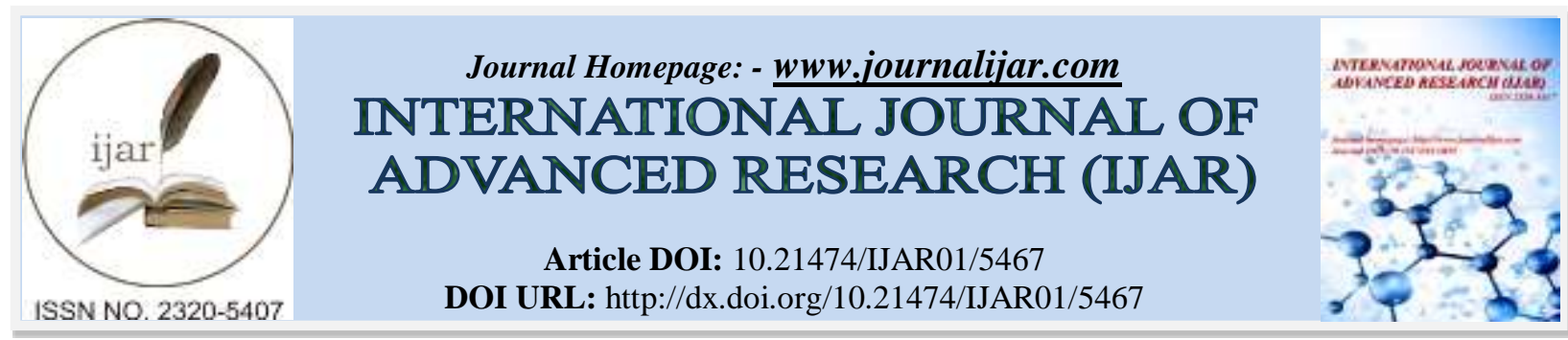

RESEARCH ARTICLE

\title{
DETERMINATION OF LACTOSE AND LACTIC ACID USING KEFIR NANOGRAINS AS SELECTIVE ALIVE MICRO-ORGANISM BY UV-VIS. SPECTROMETRY BASED ON CAPPING BEHAVIOR OF LACTIC ACID DURING FORMATION OF FEOOH NANOPARTICLES.
}

Mohammad Mahdi Doroodm and and Farideh Zare.

Department of Chemistry, College of Sciences, Shiraz University, 71454, Shiraz, Iran.

\section{Manuscript Info}

Manuscript History

Received: 19 July 2017

Final Accepted: 21 August 2017

Published: September 2017

Key words:-

Kefir grains; Lactose; Lactic acid; UV-

Vis. Spectrometry; Capping agent; $\mathrm{FeOOH}$.

\begin{abstract}
A novel UV-Vis. spectrometric technique has been introduced for determination of lactose and lactic acid using kefir nanograins as selective alive microorganism. Microorganisms such as yeast and lactic acid bacteria in the kefir matrix as enzyme during conversion of lactose to lactic acid and then lactic acid are considered as acceptable capping agent during formation of $\mathrm{FeOOH}$ species. Formation of $\mathrm{FeOOH}$ as considered is responsible active species during lactose/lactic acid determination. These alive reagents in kefir grains are selective for lactose and lactic acid determination via observation of absorption peak at around $380 \mathrm{~nm}$ depending on the size of the kefir grains. The introduced method has a linear response from $1.0 \times 10^{-6}$ to $1.0 \times 10^{-2} \mathrm{~mol}$ $\mathrm{L}^{-1}$ for lactose and $1.0 \times 10^{-5}$ to $1.0 \times 10^{-3}$ for lactic acid. Detection limits are also estimated to around $1.0 \times 10^{-7} \mathrm{~mol} \mathrm{~L}^{-1}$ and $3.0 \times 10^{-6} \mathrm{~mol} \mathrm{~L}^{-1}$ for lactose and lactic acid, respectively. More acceptable response time and detection limit was estimated for each lactose and lactic acid, compared to the general methods such as titrimetry, high-performance liquid chromatography and infrared spectrometry. This study points to the dangerous effect of the formation of $\mathrm{FeOOH}$ nanoparticles during the use of Kefir in our nutrient chain based on the catalytic effect of the kefir's microorganism and ion species and copping behavior of lactic acid.
\end{abstract}

Copy Right, IJAR, 2017,. All rights reserved.

\section{Introduction:-}

During the last decades, the dairy industry has made several attempts to improve the quality and the nutrient contents of milk-based formula. In order to develop special products for specific people, some ingredients have been added to the milk powder (Xinmin, Ruili, Zhihua, Yuanhong, \& Tingfu, 2008). For example, calcium is added to prevent osteoporosis that frequently affects the old people, while some vitamins and minerals are used in the formulae for pregnant women (Xinmin, Ruili, Zhihua, Yuanhong, \& Tingfu, 2008). Recently enriched milk with carbohydrates and carbohydrate-reduced production has been existed.

Lactose is the main carbohydrate in dairy products and is considered as the only saccharide synthesized by mammals at a concentration of 4-5\% (w/v) in cow and other mammals' and $~ 8 \%$ in the human milk (Xinmin, Ruili, Zhihua, Yuanhong, \& Tingfu, 2008). This disaccharide is catabolized into glucose and galactose monosaccharides by the

Corresponding Author:- Mohammad Mahdi Doroodmand.

Address:- Department of Chemistry, College of Sciences, Shiraz University, 71454, Shiraz, Iran. 
enzyme lactase (Xinmin, Ruili, Zhihua, Yuanhong, \& Tingfu, 2008). Lactose has many important physiological functions. It takes part in the metabolism of calcium to help the absorption of calcium in human body (Ni, Wang, \& Kokot, 2008). It plays an important role in the formation of the neural system and the growth of skin (texture), bone skeleton and cartilage in infants. Consequently it can prevent rickets and saprodontia (Ni, Wang, \& Kokot, 2008; Xinmin, Ruili, Zhihua, Yuanhong, \& Tingfu, 2008). This compound is able to develop the producing of bacillus in babies' bowels too (Ni, Wang, \& Kokot, 2008).

Each year dairy production suffers from great economical losses due to cow mastitis (Yakovleva, Buzas, Matsumura, Samejima, Igarashi, Larsson, et al., 2012). It is a serious disease in dairy animals causing reduction in milk yield as well as lowering its nutritive value such as lactose level (Atasever, Ozdemir, Gulcin, \& Irfan Kufrevioglu, 2013; Yakovleva, et al., 2012). Lactose in dairy products is also necessary for the cheese industry in order to control the fermentation processes (Yakovleva, et al., 2012). Lactose control in dairy products is especially important in lactose reduced or lactose-free products, because $\sim 75 \%$ of adults worldwide suffer from lactose intolerance (LI) (Hertzler \& Clancy, 2003; Safina, Abizgil'dina, Gabdrakhmanova, \& Safina, 2010; Yakovleva, et al., 2012). Lactose intolerance or lactose maldigestion simply describes the incomplete digestion and subsequent malabsorption of this reagent (Hertzler \& Clancy, 2003; Swagerty Jr, Walling, \& Klein, 2002).

Lactic acid is considered as a very important ingredient for many foods, chemical and pharmaceutical industries (Tango, 1999). The demand for lactic acid is expected to increase significantly in the future due to an increased interest in "Polylactic Acid" (PLA), which has diverse applications including biodegradable plastics, surgical sutures, drug delivery systems, disposable consumer products, etc. (Abdel-Rahman, Tashiro, \& Sonomoto, 2011). It is also an useful chemical platform for the production of polymers, oxychemicals, solvents, and for the biological nutrient removal in the wastewater streams (RedCorn \& Engelberth, 2016). In several biological materials, such as fruit, vegetable juices, wine, yoghourt, cheese, meat products, etc., the determination of lactic acid is used as an indicator of the fermentative processes that take place in their preparation, storage and preservation (Klopper, Angelino, Tuning, \& Vermeire, 1986; Schlimme, Lorenzen, Martin, \& Thormahlen, 1996). Lactic acid is generally produced through the microbial fermentation of starch or sugars with yields more than $90 \%$, compared to the theoretical yield (Ilmen, Koivuranta, Ruohonen, Suominen, \& Penttila, 2007). Many species have been used for lactic acid production; however "Streptococcus" and other lactic acid bacteria are the most frequently used microorganisms (Tango, 1999).

Determination of lactose and lactic acid has been considered by scientists during the last years. Various methods have been used for lactose determination such as gravimetry (Lane \& Eynon, 1934), colorimetry (Nickerson, Vujicic, \& Lin, 1976), high-performance liquid chromatography (HPLC) (Xinmin, Ruili, Zhihua, Yuanhong, \& Tingfu, 2008), infrared spectroscopy (IR) (Luinge, Hop, Lutz, Van Hemert, \& De Jong, 1993) and methods such as colorimetric method, (Heinemann \& Hald, 1940) HPLC technique, (Riva \& Bisognani, 1972) as well as IR absorption (Andersson \& Hedlund, 1983) have also been described for lactic acid determination.

In spite of introduction of various methods for determination of lactose and lactic acid, the common points often in all reviewed articles are that, these analytical techniques are sometimes limited due to the problems such as difficulties, low selectivity, narrow linearity, high cost, toxic reagent, low sensitivity and/or less improved detection limits. All of these limitations reveal strong demand for selective, sensitive and fast determination of lactose and lactic acid in the presence of other carbohydrates and acids in different real samples. To solve these challenges, in this research a new method is introduced using kefir grains for spectrophotometric determination of lactose and lactic acid during the catalytic process.

Kefir has been originally made in the Balkans, Eastern Europe and the Caucasus (Fontán, Martínez, Franco, \& Carballo, 2006). It differs from other fermented products in its starter, which exists in the form of grains. In most cases yoghurt and cheese are used as starter cultures (Goncu \& Alpkent, 2005; Simova, Beshkova, Angelov, Hristozova, Frengova, \& Spasov, 2002) in the nutrient chain. The grains are elastic, slimy, varying from white to light yellow in color, and with an irregular and lobed shaped cauliflower-like structure of different sizes, generally ranged between 1-3 cm in length (Gao, Gu, Ruan, Chen, He, \& He, 2012; Garofalo, Osimani, Milanović, Aquilanti, De Filippis, Stellato, et al., 2015). They behave as biologically vital organisms and grow, propagate and pass their properties on to the following generations of new grains. The microflora of the kefir grains is remarkably stable, retaining its activity for years during preserving and incubating under appropriate cultural and physiological conditions (Simova, Beshkova, Angelov, Hristozova, Frengova, \& Spasov, 2002). Kefir grains contain a complex 
microbial symbiotic mixture of lactic acid bacteria (LAB), acetic acid bacteria, lactose-fermenting as well as nonlactose-fermenting yeasts, and mycelia-forming fungi (Gao, Gu, Ruan, Chen, He, \& He, 2012; Serafini, Turroni, Ruas-Madiedo, Lugli, Milani, Duranti, et al., 2014). This cluster of microorganisms is held together by a polysaccharide, named as "Kefiran", and protein matrix (Enikeev, 2012).

\section{Materials and methods:-}

\subsection{Materials}

All the chemical reagents were from their analytical grades and were used as received without any further purification. The kefir grains as starter culture inside the milk (Pegah, Shiraz, Iran, \%Fat=2.5) with the average grain diameters of $\sim 2.0 \mathrm{~cm}$ were purchased from market (Shiraz, Iran, home-made, Purchased date: March, 2014). HCl $(37 \%, \mathrm{~W} / \mathrm{W}, \mathrm{Merck})$ and $\mathrm{NaOH}$ crystals (Merck, Analytical grades) were adapted to control and fix the $\mathrm{pH}$ of the solutions. 50.0- $\left.\mathrm{mL} \mathrm{Fe}^{3+}(0.1 \mathrm{~mol} \mathrm{~L})^{-1}\right)$ and the same volume of $\mathrm{Cu}^{2+}\left(0.1 \mathrm{~mol} \mathrm{~L}^{-1}\right)$ standard solutions were prepared via dissolving $2.02 \mathrm{~g} \mathrm{Fe}\left(\mathrm{NO}_{3}\right)_{3} .9 \mathrm{H}_{2} \mathrm{O}$ reagent (Merck) and $0.852 \mathrm{~g} \mathrm{CuCl}_{2} \cdot 2 \mathrm{H}_{2} \mathrm{O}$ (Merck) in $50.0 \mathrm{~mL}$ volumetric flasks and diluted to the mark by triply-distilled water. For lactose and lactic acid determination, lactose. $\mathrm{H}_{2} \mathrm{O}$ (Fluka, GMW: $360.32 \mathrm{~g} \mathrm{~mol}^{-1}$ ) and lactic acid (Merck, GMW: $\left.90.08 \mathrm{~g} \mathrm{~mol}^{-1}\right)$ stock solutions $(0.01$ and $0.1 \mathrm{~mol} \mathrm{~L}$, respectively) were prepared via dissolving $0.901 \mathrm{~g}$ lactose (in $250 \mathrm{~mL}$ flask) and $827 \mu \mathrm{L}$ lactic acid (in $100.0 \mathrm{~mL}$ volumetric flask), followed by dilution to the marks using triply-distilled water. Soluble aqueous solutions including different cations and anions such as $\mathrm{K}^{+}, \mathrm{Ca}^{2+}, \mathrm{Mg}^{2+}, \mathrm{Na}^{+}, \mathrm{Cl}^{-}, \mathrm{SO}_{4}{ }^{2-}, \mathrm{PO}_{4}{ }^{3-}$, etc. were individually selected as foreign species to study the interfering effects. All these reagents were from Merck Company. $\mathrm{ZnCl}_{2}$ was also from Fluck. Also vitamins such as $B, C, D, E, K$ and $A$ were purchased from Darou Pakhsh-Iran Company. Acetic acid (GMW: $60.05 \mathrm{~g} \mathrm{~mol}^{-1}$ ) from Merck company was used to study the interfering effect with lactic acid. Disaccharides such as $\mathrm{D}(+)$-sucrose were from Fluka Company. Analytical grade of D (+) glucose. $\mathrm{H}_{2} \mathrm{O}$ were from Merck Company. For this purpose, soluble aqueous solutions of these reagents were individually prepared via spiking 100-fold excess of $\mathrm{Zn}^{2+}, \mathrm{Mg}^{2+}, \mathrm{Na}^{+}, \mathrm{K}^{+}, \mathrm{Ca}^{2+}, \mathrm{Cl}^{-}, \mathrm{SO}_{4}{ }^{2-}, \mathrm{PO}_{4}{ }^{3-}$, glucose and sucrose, spiked into the lactose standard solutions $(0.1$ $\left.\mathrm{mmol} \mathrm{L}{ }^{-1}\right)$. For this purpose $50.0 \mathrm{~mL}$ stock solution $\left(0.1 \mathrm{~mol} \mathrm{~L}^{-1}\right)$ of these reagents were individually prepared via dissolving 1.017, 0.292, 0.373, 0.871, 0.555, 0.820, 1.438, 0.681, 0.991, and $1.712 \mathrm{~g} \mathrm{MgCl}_{2} .6 \mathrm{H}_{2} \mathrm{O}, \mathrm{NaCl}^{\mathrm{KCl}}$, $\mathrm{K}_{2} \mathrm{SO}_{4}, \mathrm{CaCl}_{2}, \mathrm{Na}_{3} \mathrm{PO}_{4}, \mathrm{ZnSO}_{4} .7 \mathrm{H}_{2} \mathrm{O}, \mathrm{ZnCl}_{2}, \mathrm{D}(+)$ glucose. $\mathrm{H}_{2} \mathrm{O}$ and $\mathrm{D}(+)$-sucrose, respectively, as the probably foreign species to study the effect of interfering effects.

\subsection{Apparatus}

To prepare the micro-emulsion of kefir/water, a microwave oven (model: Samsung, power: 1200 W) with temperature programming system was utilized. The $\mathrm{pH}$ of the solutions was controlled using a $\mathrm{pH}$ meter (Model: Metrohm 827). A centrifuge (model: Hettich) with $5000 \mathrm{rpm}$ was used to eliminate the interfering agents. A UVVis. spectrophotometer (model: ultrospec 4000) was also selected using a 1.0-cm quartz cell. Titrimetry and HPLC were selected as standard reference methods to evaluate the reliability of this method for lactose and lactic acid determination. Turbidity of the solutions was evaluated using a turbidimeter (model: 965 Digital Turbidimeter, Orbeco-Hellige). The particle size analyzer (model: Horvia LB-550) was used for analyzing the particles of the kefir-containing solutions and transmission electron microscopy (TEM) (model: Zeiss-EM10C-80KV, 250 kV) was used to image the generated the $\mathrm{FeOOH}$ nanoparticles.

\subsection{Generation and growth of kefir grains}

To generate and grow the kefir grains, $\sim 20 \mathrm{~g}$ of small nucleolus of kefir grains (size: 1-3 cm) was purchased from market (Shiraz, Iran, home-made, Purchased date: March, 2014) and inserted into a 100-mL fatty milk sample $(\% \mathrm{Fat}=2.5, \mathrm{~W} / \mathrm{W})$ inside a $500-\mathrm{mL}$ glass container. After hand shaking the medium for homogenizing the suspension, it was put inside a dark condition for $\sim 2-3$ days. The kefir grains were then grow and settled down with each other at the bottom of the container. After decanting the suspension above the kefir grains, it was separated and inserted inside a-100 mL milk $(\% \mathrm{Fat}=2.5, \mathrm{~W} / \mathrm{W})$ and protected at dark conditions at room temperature. To provide the kefir grains, the reagent was separated and after slowly washing with $\sim 500 \mathrm{~mL}$ triply-distilled water; it was dried using a general blow drier at $58 \pm 2{ }^{\circ} \mathrm{C}$ temperature and weighted for the analytical purposes. For preparation of lactose standard solution, 2.50 and $0.25 \mathrm{~mL}$ of each $\mathrm{Fe}^{3+}\left(0.1 \mathrm{~mol} \mathrm{~L}^{-1}\right)$ and $\mathrm{Cu}^{2+}\left(0.1 \mathrm{~mol} \mathrm{~L}{ }^{-1}\right)$ solutions were inserted into a $25.0-\mathrm{mL}$ volumetric flask. Then $\sim 6.0 \mathrm{~mL}$ of the kefir nanograin-sustaining solution was added. This reagent was used for selective determination of lactose in the presence of lactic acid.

\subsection{Preparation of kefir suspension}

To prepare kefir suspension, $\sim 20 \mathrm{~g}$ kefir grains were inserted into about $200.0 \mathrm{~mL}$ pastoralized milk with semi-fat percentage $(\% \mathrm{Fat}=2.5, \mathrm{~W} / \mathrm{W})$ for $\sim 2-3$ days inside a closed glass tubing at dark condition. The kefir reagent was 
then washed with water the triply-distilled water $(\sim 500 \mathrm{~mL})$. After drying by a general blow drier, it was weighted at the optimum condition. This reagent was inserted inside a $17 \pm 2 \mathrm{~mL}$ triply-distilled and irradiated with microwave radiation at $680-\mathrm{W}$ power for $20 \mathrm{~s}$ time duration using a microwave oven. The number of microwave pulses should be controlled to have temperature to maximum $60{ }^{\circ} \mathrm{C}$. The aqueous solution was finally decanted from the kefir grains and adopted as kefir nanograin-sustaining solution.

\subsection{Procedure}

Determination of lactose and lactic acid was achieved under optimized conditions such as room temperature, [Fe $\left.{ }^{3+}\right]$ $=0.01 \mathrm{~mol} \mathrm{~L}^{-1},\left[\mathrm{Cu}^{2+}\right]=1.0 \mathrm{mmol} \mathrm{L}{ }^{-1}$, quantity of kefir $=4.00 \pm 0.03 \mathrm{~g}$, microwave power $=680 \mathrm{~W}$ with time duration of $20 \mathrm{~s}, \mathrm{pH}=2.0$ and high ionic strength. For this purpose the procedure was partially the same as that reported in the previous section (sections: 2.3 and 2.4). Briefly $\sim 20 \mathrm{~g}$ of kefir grains were inserted into $\sim 200.0 \mathrm{~mL}$ of pastoralized milk with semi-fat percentage $(\%$ Fat $=2.5)$ for about 2-3 days inside a closed glass tubing at dark condition. Then kefir reagent was washed with water triply-distilled water $(\sim 500 \mathrm{~mL})$ and after drying by the general blow drier, it was then weighted at the optimum condition. This reagent was inserted inside a $17 \pm 2 \mathrm{~mL}$ of triply-distilled and irradiated with microwave radiation at $680-\mathrm{W}$ power for $20 \mathrm{~s}$ time durations at temperature up to maximum $60{ }^{\circ} \mathrm{C}$. The aqueous solution was then decanted from the kefir grains and transferred into a 50.0-mL volumetric flask. Before dilution of the solution to the mark using triply-distilled water, the concentrations of each $\mathrm{Fe}^{3+}$ and $\mathrm{Cu}^{2+}$ ions were set to 0.01 and $0.001 \mathrm{~mol} \mathrm{~L}^{-1}$, respectively. The prepared kefir grains as alive reagents were selective for lactose determination via observation of absorption peak at maximum wavelength to around $380 \mathrm{~nm}$. For determination of lactic acid the same procedure was repeated without using any kefir (i.e. any nanograin-sustain) and $\mathrm{Cu}^{2+}$ according to the preparation procedure. For the determination process the absorbance intensities were measured using the UV-Vis. spectrometer at the maximum wavelength.

To validate the proposed analytical approach, an analytical test was performed. Standard addition methods were selected for determination of lactose and lactic acid in different milk solutions and dairy samples, followed by comparison with the results obtained by titrimetry and HPLC methods, respectively, according to a reference (Lane \& Eynon, 1934). Also, probable effects of some interfering agents were eliminated according to the recommended procedure.

\section{Result and discussion:-}

In this study, microorganisms in the kefir grains played role via two different pathways. In the first pathway lactose was converted to lactic acid during the metabolism, whereas in the former pathway the generated lactic acid converted $\mathrm{Fe}^{3+}$ to products such as $\mathrm{FeOOH}$. But the utilization of this alive microorganism was limited due to the challenges such as hard procedure for collection, as well as separation and growth of the microorganisms in the nutrient medium. The use of these microorganisms has provided challenges like low life time during their deactivation and also necessity for their use in the sterilized conditions. It has been reported that, kefir grains due to the possessing characteristics such as green reagents, low cost and their simple growth, can be selected as good candidate for sensitive determination of lactose and lactic acid. Parameters having strong influence during determination of lactic acid include: kind, amount and size of kefir grains, effect of microwave radiation, influence of catalytic reagents such as $\mathrm{Fe}^{3+}$ and $\mathrm{Cu}^{2+}$, etc. These parameters were optimized using one-at a time method.

\subsection{Optimization of total determination lactose and lactic acid \\ 3.1.1. Effect of kefir}

To evaluate the effect of kefir during determination of lactose and lactic acid, the UV-Vis. spectra of the solutions containing lactose $\left(1.0 \mathrm{mmol} \mathrm{L}^{-1}\right)$ and lactic acid $\left(0.1 \mathrm{mmol} \mathrm{L}^{-1}\right)$ were studied in detail in the presence of kefir grain suspension (\% $0.235 \mathrm{w} / \mathrm{v}$ ). Based on the results, no significant effect was observed in the absorbance wavelength during determination of lactic acid. Whereas surprisingly major enhancement was observed in the intensity of the absorbance for lactose, whereas there was an inversion slope for lactic acid. This effect was initially attributed to the presence of trace quantity of lactic acid in the blank solution, however could be considered as a key point for recognition of the mechanism. Based on the spectra, kefir grains were considered as an effective microorganism during their interactions with lactose. To evaluate this effect, it was initially focused on the effect of microorganism for the lactose determination.

\subsubsection{Size and morphology of kefir grains}

Size and morphology of kefir grains were also evaluated as important parameter. To evaluate the size of kefir grains on the sensitivity during the lactose and lactic acid determination, kefir grains with different average sizes such as $~$ 
1, 2, and $3 \mathrm{~cm}$ were tested under the similar conditions. However, these sizes may be under the influences of their nutrient sources, seasons and nutrient mediums during their growth. Maximum sensitivity was obtained during using kefir grains with average diameter of $\sim 2 \mathrm{~cm}$. Therefore, this size was selected and used. It seemed that, factors such as active surface area, population of the alive microorganisms on the surface of kefir colony and probably some attraction forces (coagulation factor) between kefir nucleuses were the main reasons for selection of the average size of the kefir grains.

\subsubsection{Optimum amount of kefir}

The first factor having strong influence on determination of lactose was the quantity of kefir grains. To optimize this factor, different amounts of kefir grains ranging between $0.1-5.0 \mathrm{~g}$ were weighted and contacted with lactose standard solution with $0.1 \mathrm{mmol} \mathrm{L}^{-1}$ concentration. The results are as shown in Fig. 1. As clearly seen, maximum sensitivity was observed for kefir grains as large as $4.0 \pm 0.03 \mathrm{~g}$. At lower amounts of kefir, the sensitivity was low, whereas at quantities larger than $4.0 \pm 0.03 \mathrm{~g}$, the response was partially fixed and stable. Therefore, $4.0 \pm 0.03 \mathrm{~g}$ kefir grains were selected as optimum weight during determination of lactose.

\subsubsection{Microwave-assisted UV-Vis. spectrometry}

To promote the sensitivity of the detection system during determination of lactose and lactic acid, effects of some factors such as microwave radiations, ultrasonic irrational as well as thermal heating were also investigated in detail. It seemed that these factors could increase the active surface area of the kefir grains during its interaction with lactose. For this purpose, a microwave oven with temperature programming system was adopted with electrical power ranging between $170-850 \mathrm{~W}$. Also, an ultrasonic probe with frequency of 50-60 Hz was utilized to evaluate the sensitivity of the system. The temperature of the solution was also controlled via suspension of the glass tubing sample inside a water bath at temperature ranging between 2 to $40{ }^{\circ} \mathrm{C}$. Based on the results, no significant influence was observed during direct heating of the solution to $2-40{ }^{\circ} \mathrm{C}$. Also, the effect of ultrasonic irradiations was not majorly effective. Significant enhancement was observed during radiation of samples with microwave. The inset of Fig. 2 showed the histogram of absorbance intensity vs. different microwave powers between 170 to $850 \mathrm{~W}$ during analysis of $0.1 \mathrm{mmol} \mathrm{L}^{-1}$ lactose standard solution. As clearly exhibited, maximum intensity was observed for $680-$ $\mathrm{W}$ microwave power that was consequently selected as optimum power. Another important factor about the microwave radiation was the time duration of microwave radiations.

Fig. 1.SP showed the relationship between the UV-Vis. absorbance intensity vs. different time durations of microwave radiation of lactose $\left(0.1 \mathrm{mmol} \mathrm{L}^{-1}\right)$ at the optimized power. According to the results, time duration as long as $20 \mathrm{~s}$ was selected as the optimum time. At this condition, the temperature of the solution was estimated to $\sim$ $60{ }^{\circ} \mathrm{C}$.

In this study the reusability of the kefir grains was also evaluated. For this purpose, the suspension containing the kefir grains were irradiated with microwave radiation every 3-4 h, simply via exchanging the water medium above the kefir gains. The relative standard deviation (RSD) during sequential analyses $(n=3)$ of lactose determination $(0.1$ mmol L $\mathrm{L}^{-1}$ ) was estimated to be $12 \%$. This observation was attributed to the stability and activity of the microorganisms inside the kefir grains even after the microwave irradiation. After this time period, the grain structure of the kefir was changed into a soft gelatin. It should be noted that this activity was not amended even by providing the adequate nutrient solution. This effect, therefore, provided challenges such as colloidal behavior of the decanted solution that limited the reusability of the kefir grains.

\subsubsection{Dilution factor of the blank solution}

Another important factor that usually needed to be evaluated during analysis of samples dealing with the microorganisms was the dilution factor of the blank solution. Based on the results, analysis of lactose standard solution $\left(0.1 \mathrm{mmol} \mathrm{L}^{-1}\right)$ under the similar conditions without diluting the blank solution led to have an absorbance peak with negative intensity. This effect was eliminated during diluting the blank solution for about several times (Fig. 2.SP). This surprising effect was probably attributed to the presence of some effective species inside the blank that was deactivated during the dilution processes. This effect was, therefore, considered as an important factor that could be adopted for estimation of the mechanism of the process. This phenomenon was also attributed to some phenomena such as i) presence of a fixed memory effect such as some residual adsorbed lactose in the kefir matrix during its growth in the nutrient medium (milk environment), and ii) turbidity of the blank solution, probably during formation of some species. 


\subsubsection{Optimum concentration of inorganic species as catalyst}

Inorganic additives such as $\mathrm{Fe}^{3+}, \mathrm{Cu}^{2+}$, etc. were considered as suitable catalysts during interaction between lactose and kefir grains. Among different tested anions and cations, $\mathrm{Fe}^{3+}$ and $\mathrm{Cu}^{2+}$ were considered as suitable species for enhancing the sensitivity during interaction between kefir and lactose. Fig. 3 shows the diagrams of absorbance intensities vs. different concentrations of each $\mathrm{Fe}^{3+}$ and $\mathrm{Cu}^{2+}$ species. Maximum absorbance intensity was evaluated for $\mathrm{Fe}^{3+}$ and $\mathrm{Cu}^{2+}$ species with molar concentrations the same as $0.01 \mathrm{~mol} \mathrm{~L}^{-1}$ and $1.0 \mathrm{mmol} \mathrm{L}^{-1}$, respectively. These results were accepted as optimum concentrations during determination of lactose and lactic acid. It also seemed that, the cooperative catalytic effect of these two ions was the main reason for the rate of $\mathrm{Fe}^{3+}$ and $\mathrm{Cu}^{2+}$ during the lactose/lactic acid analyses.

Stable interaction was existed between $\mathrm{Fe}^{3+}$ and lactic acid according to the UV-Vis. The use of $\mathrm{Fe}^{3+}$ and $\mathrm{Cu}^{2+}$ as needed ionic species during the catalytic effect of the microorganism has also been previously reported in Ref. (Halliwell \& Gutteridge, 1985). Interaction between lactose and kefir probably led to the formation of lactic acid (Gao, Gu, Ruan, Chen, $\mathrm{He}, \& \mathrm{He}, 2012$ ). Therefore, each $\mathrm{Fe}^{3+}$ and $\mathrm{Cu}^{2+}$ ions from one side played role as catalyst for conversion of lactose to lactic acid and from the other hand $\mathrm{Fe}^{3+}$ acted as selective reagent for the formation of ferric oxyhydroxy $(\mathrm{FeOOH})$ during the lactic acid determination. Maximum UV-Vis. absorbance wavelength was shifted from $\sim 250$ to $\sim 380 \mathrm{~nm}$ due to the formation of $\mathrm{FeOOH}$ nanoparticles during the conversion of the $\mathrm{Fe}^{+3} /$ lactic acid complex.

\subsubsection{Effect of $\mathrm{pH}$ and ionic strength}

In this experiment, effect of $\mathrm{pH}$ was evaluated in detail. For this purpose, $0.01 \mathrm{~mol} \mathrm{~L}^{-1}$ solution of universal buffer $\left(\mathrm{H}_{3} \mathrm{PO}_{4}, \mathrm{H}_{3} \mathrm{BO}_{3}, \mathrm{CH}_{3} \mathrm{COOH}\right.$ and $\left.\mathrm{NaOH}\right)$ was adopted. Maximum absorbance intensity was observed at $\mathrm{pH} \sim 9.0$. Consequently, this $\mathrm{pH}$ was selected as the optimum value and validated with $0.01 \mathrm{~mol} \mathrm{~L}^{-1}$ ammonia buffer solution $\left(\mathrm{NH}_{3} / \mathrm{NH}_{4}{ }^{+}\right)$, in which ammonia also acted as auxiliary complexing agent at the basic conditions. However, when using $\mathrm{Fe}^{3+}$ and $\mathrm{Cu}^{2+}$ species as suitable catalytic probe, the $\mathrm{pH}$ value of the solution was suddenly shifted to $\mathrm{pH} \sim 2.0$. This phenomenon was due to the intrinsic behavior of each $\mathrm{Fe}^{3+}$ and $\mathrm{Cu}^{2+}$ that played role as strong Lewis acid (Pfennig, 2015; Rimstidt, 2013). At this condition, as the absorbance intensities were evaluated at strong acidic conditions, therefore, there was no need to control the $\mathrm{pH}$ of the solution before each analysis. Also at this condition, the ionic strength of the solution was high $\left(\sim 0.05 \mathrm{~mol} \mathrm{~L}^{-1}\right)$. Therefore, there was not necessary to control the ionic strength of the solution.

\subsubsection{Effect of oxygen}

Effect of oxygen during interactions of kefir grains with lactose was investigated in detail. For this purpose, UV-Vis. spectra of lactose standard solution $\left(0.1 \mathrm{mmol} \mathrm{L}^{-1}\right)$ under the optimized condition were evaluated during purging $\mathrm{N}_{2}$ gas into the solution. No major changes (maximum differences: $~ 0.45 \%$ ) were observed in the sensitivity in the presence or absence of the dissolved oxygen. Therefore, there was no need to control the quantity of dissolved oxygen during the lactose/lactic acid determination.

\subsection{Optimization during lactic acid determination}

During the optimization of lactic acid, effects of parameters such as kefir grains, temperature, effective roles of $\mathrm{Fe}^{3+}$ and $\mathrm{Cu}^{2+}, \mathrm{pH}$ and ionic strength were investigated in detail.

\subsubsection{Effect of kefir grains}

In spite of the effective role of kefir grains during analysis of total amounts of lactose/lactic acid, no significant influence was observed during the selective determination of lactic acid.

\subsubsection{Effect of $\mathrm{Fe}^{3+}$ and $\mathrm{Cu}^{2+}$ species during lactic acid determination}

The catalytic effects of each $\mathrm{Fe}^{3+}$ and $\mathrm{Cu}^{2+}$ species were also evaluated in detail. As explained in detail in the previous sections, both $\mathrm{Fe}^{3+}$ and $\mathrm{Cu}^{2}$ species were effective, therefore the influence of these species should be evaluated during selective determination of lactic acid. For this purpose, the UV-Vis. spectra of standard lactic acid solution $\left(0.01 \mathrm{~mol} \mathrm{~L}^{-1}\right)$ containing $\mathrm{Fe}^{3+}\left(1.0 \mathrm{mmol} \mathrm{L}^{-1}\right)$ and $\mathrm{Cu}^{2+}\left(1.0 \mathrm{mmol} \mathrm{L}{ }^{-1}\right)$ species, were studied in detail according to the results shown in Fig. 2.SP. Based on the results (Fig. 2.SP), positive effect was observed during addition of $\mathrm{Fe}^{3+}$ to the lactic acid-containing solution, whereas negative influence (reduction in the UV-Vis. absorbance) was observed during the introduction of $\mathrm{Cu}^{2+}$ to the solution matrix. This behavior was attributed to the formation of complex between lactic acid and $\mathrm{Fe}^{3+}$ during the formation of product(s) as selective chromophore 
during the determination of lactic acid. Therefore, it was only focused on optimization of $\mathrm{Fe}^{3+}$ solution. Optimum concentration of $\mathrm{Fe}^{3+}$ was obtained at $0.01 \mathrm{~mol} \mathrm{~L}^{-1}$ concentration.

\subsubsection{Effect of temperature}

Effect of temperature was also evaluated in detail. Significant changes were observed on the yellow color of the lactic acid standard solution in the presence of $\mathrm{Fe}^{3+}$ species $\left(0.01 \mathrm{~mol} \mathrm{~L}^{-1}\right)$ that was related to the formation of $\mathrm{FeOOH}$ nanoparticles. But as $\mathrm{Fe}^{3+}$ aqueous solution could be converted to $\mathrm{FeOOH}$ by direct heating (Genin, Toullec, Antoniotti, Brancour, Genet, \& Michelet, 2006), therefore there was not necessary to heat the solution directly or using inductive heating sources such as irradiation with microwave radiations. This result was considered as another important observation during evaluation of the mechanism in determination of lactose and lactic acid species.

\subsubsection{Effect of $\mathrm{pH}$ and ionic strength during lactic acid determination}

Due to the acidic property of $\mathrm{Fe}^{3+}$, the $\mathrm{pH}$ of the solution was fixed at $\sim 2$. Therefore there was no need to control the $\mathrm{pH}$ and ionic strength during lactic acid determination.

\subsection{Analytical figures of merit}

Maximum absorbance intensity was observed at around $380 \mathrm{~nm}$ (depending on size of kefir grains) that was selected for determination of each lactose and lactic acid. The calibration curves for lactose and lactic acid were illustrated in Figs. 4.A and 4.B, respectively. The introduced microorganism was suitable for lactose and lactic acid determination yielded linear dynamic range between $1.0 \times 10^{-6}$ to $1.0 \times 10^{-2} \mathrm{~mol} \mathrm{~L}^{-1}$ for lactose and between $1.0 \times 10^{-5}$ to $1.0 \times 10^{-3} \mathrm{~mol} \mathrm{~L}^{-1}$ for lactic acid.

The detection limit (DL) was defined as the triple values of the standard deviation of the blank divided by the calibration sensitivity (slopes of the calibration curves, Figs. 4.A and 4.B). Based on this definition, the limit of detection (LOD) was found as $1.0 \times 10^{-7} \mathrm{~mol} \mathrm{~L}^{-1}$ for lactose and $3.0 \times 10^{-6} \mathrm{~mol} \mathrm{~L}^{-1}$ for lactic acid species.

The sensitivity of this method was evaluated according to the slopes (calibration sensitivity) of the calibration curves (Figs. 4.A and 4.B). These values were evaluated to 133.22 (a.u.) $\mathrm{M}^{-1}$ for lactose and 686.76 (a.u.) $\mathrm{M}^{-1}$ for lactic acid species. High sensitivity of this method was strongly attributed to the intrinsic behavior of the kefir grains as the selective microorganism. Significant difference between the calibration sensitivities was attributed to the effect of kefir grains. As expected, this factor was strongly dependent to some different parameters such as i) microwave radiation during lactose determination, ii) concentration of the nutrient medium at which the kefir gains were existed, and iii) finally the average size of kefir grains during their growth inside the nutrient medium. It should be noted that, besides the effective role of microwave radiation on the formation of nano-fluid, microwave radiation had little destructive effect on the kefir grains during its uses for the lactose determination.

The relative standard deviation (RSD \%) during several analyses $(\mathrm{n}=3)$ of lactose with $0.1 \mathrm{mmol} \mathrm{L}^{-1}$ concentration was $12.04 \%$, which pointed to this fact that microwave radiation had destructive effect to some extent. However, because of some characteristics of the kefir grains such as their low cost, availability, ease of growth, and their biocompatibility, this factor seemed to be negligible. Therefore, to analyze trace quantity of lactose, it was recommended to select microwave-assisted UV-Vis. spectrometry.

The RSD \% for lactic acid $(1.0 \mathrm{mM})$ was $0.45 \%$ during 3 sequential analyses. However this value was increased after more than $4-5 \mathrm{~h}$ time intervals. Factors such as the lack of homogeneity of the kefir gains at solid state were the main reason for the value of RSD\% during different replicate analyses. Therefore, population of microorganisms inside a constant quantity of kefir grains was not controllable, even during applying the same conditions such as a fixed matrix for the nutrient medium. The RSD\% (reproducibility) was estimated to $12 \%$ for 4 replicate analyses of lactic acid $(1.0 \mathrm{mM})$ under the optimized condition. This difference was attributed to the alive behavior of microorganisms inside the kefir matrix. Therefore, to get reliable results during estimating the quantity of lactose in the real sample, it was recommended to analyze the samples with a constant and fresh suspension of kefir during about 3-4 h time intervals.

No interference was observed in the presence of at least 100-fold excess of some foreign species such as sweeting saccharides such as glucose and sucrose. Also, no interfering effect was observed during testing 100-time excess of ions such as $\mathrm{Mg}^{2+}, \mathrm{Na}^{+}, \mathrm{Cl}^{-}, \mathrm{Ca}^{2+}, \mathrm{PO}_{4}{ }^{3-}$, and $\mathrm{SO}_{4}{ }^{2-}$ inside $0.1 \mathrm{mmol} \mathrm{L}{ }^{-1}$ lactose. This phenomenon clearly revealed 
the stability of the kefir grains in the presence of various cations and anions. Probable effect of some interfering effects such as fat, casein, vitamins $A, B, C, D, E$ and $K$ as well as the interference of $\mathrm{Zn}^{2+}$ (50-fold excess) were eliminated during the separation process according to the following recommended procedure. For determination of lactic acid, there was no interfering effect in the presence of some tested foreign species such as acetic acid, vitamins $\mathrm{C}$ and $\mathrm{B}_{6}$ inside the real samples.

\subsection{Elimination of interfering agents}

For determination of lactose in the milk real samples during elimination of the probable interfering effects, water insoluble reagents such as milk fats as well as vitamins $A, D, E$ and $K$ were omitted via centrifuging the initial real samples with $\sim 5000 \mathrm{rpm}$ for $\sim 10 \mathrm{~min}$. The $\mathrm{pH}$ of the centrifuged reagent was set to $\sim 11.0$ using concentrated $\mathrm{NaOH}$ to precipitate the hydroxide salts reagents such as $\mathrm{Zn}^{2+}$, which had interfering effect (relative error percentage: $\sim 68$ $\%)$. This $\mathrm{pH}$ also led to totally eliminate the interfering effect of some water soluble vitamins such as vitamins $C$ and $B$ during formation of insoluble micelle throughout their reaction with casein and $\mathrm{Ca}^{2+}$ (Cross, Huq, Palamara, Perich, \& Reynolds, 2005; Horne, 2006; McMahon \& McManus, 1998), naturally contained inside the milk matrix. After separation of the precipitations by centrifuging ( $\mathrm{rpm}=5000$ for about $10 \mathrm{~min}$ ), the $\mathrm{pH}$ of the milk was set to the isoelectric $\mathrm{pH}$ of casein (i.e. $\mathrm{pH} \sim 6.4$ ). This process led to separate the excess quantity of casein inside the milk solution during the centrifuging (Andrei, 2008). As trace amounts of water soluble vitamins were so sensitive to the microwave radiations, the aqueous reagent was then irradiated with microwave radiation at $170-\mathrm{W}$ power for $20 \mathrm{~s}$ with 5-s time duration, for totally elimination of the residual water soluble vitamins, which probably had not been totally separated during the precipitation process. This process therefore led to have complete elimination of any residual interfering agents from the sample. In this process, centrifuging was also needed for the final solution. This process also led to have milk serum solution. For determination of lactic acid in dairy products, there were no interfering effects from vitamins $B$ and $C$, acetic acid, etc.

The enrichment factor the milk reagents was estimated between 100-200 depending on the milk factory. Due to the presence of these concentrations outside the linear ranges, therefore dilution of the solution between 100-200 times was needed depending on the enrichment factor. For determination of lactic acid, the real samples were diluted 200 times using triply-distilled water. After final centrifuging, the analytes were analyzed according to the recommended procedure.

\subsection{Real sample analysis}

The validation of the method was evaluated by an analytical test via comparison between this method and titrimetry (Lane \& Eynon, 1934) for lactose determination, and HPLC (Andersson \& Hedlund, 1983) for lactic acid determination as reference and accepted analytical methods, followed by estimation of the relative error percentages. The results were shown in Table 1. Good agreement was obtained during comparing the results of the developed method with titrimetry (Lane \& Eynon, 1934) and HPLC (Andersson \& Hedlund, 1983), revealing the reliability and acceptance of the developed method for lactose and lactic acid determination.

\subsection{Proposed behavior of the reactions}

Formation of $\mathrm{FeOOH}$ was responsible active species during the lactose/lactic acid determination. In another word, lactic acid was considered as acceptable capping agent (Deng, Cheng, Jin, Qi, \& Xiao, 2012; Jamshidi, Hyon, \& Ikada, 1988) during formation of $\mathrm{FeOOH}$ species. The evidences related to this claim are as follows:

- Good agreement was observed between the yellow colors of FeOOH-containing solution (Genin, Toullec, Antoniotti, Brancour, Genet, \& Michelet, 2006) and the result directly observed in this study.

- Effect of temperature during formation of yellow solution was in good agreement with the hydrolysis of $\mathrm{Fe}^{3+}$ species during formation of FeOOH species as reported in Ref. (Genin, Toullec, Antoniotti, Brancour, Genet, \& Michelet, 2006) according to the following chemical equilibrium (Eq. 1) :

- Good correlation was observed at around $380 \mathrm{~nm}$ for $\mathrm{FeOOH}$ nanoparticles, synthesized in the presence of lactic acid (in this study) with that generated during reaction between $\mathrm{Fe}^{3+}$ and hydrazine at $2.0 \mathrm{~atm}$. pressure according to literature (Qiao, Yang, \& Gao, 2009). The UV-Vis. spectrum is shown in Fig. 4.SP.

For getting further information about the formation of $\mathrm{FeOOH}$ species, the $\mathrm{FeOOH}$ solution synthesized in the presence of lactic acid was bubbled with CO gas (99.99, Linde, Germany) with several $\mathrm{mL} \mathrm{min}^{-1}$ flow rates for $\sim 15$ min. According to Eq. 2, reaction between $\mathrm{FeOOH}$ and $\mathrm{CO}$ led to the formation of $\mathrm{Fe}_{3} \mathrm{O}_{4}$ and $\mathrm{CO}_{2}$ (Qiao, Yang, \& Gao, 2009). Based on the results (Fig. 5.SP), 30\% reduction was observed in the absorbance intensity due to formation of $\mathrm{Fe}_{3} \mathrm{O}_{4}$. 
To attribute this reduction $(\sim 30 \%)$ only to the decrease in the amount of $\mathrm{FeOOH}$ and formation of $\mathrm{Fe}_{3} \mathrm{O}_{4}$, the absorbance intensity of $\mathrm{Fe}^{3+}$ solution $\left(0.01 \mathrm{~mol} \mathrm{~L}^{-1}\right)$ before and after introduction of $\mathrm{CO}$ gas (i.e. formation of $\mathrm{Fe}(\mathrm{CO})_{5}{ }^{3+}$ ) was evaluated in detail. There was no significant change was observed in the absorbance intensity at $\sim 330 \mathrm{~nm}$. Therefore, formation of $\mathrm{FeOOH}$ was considered as the responsible product during the determination process.

Effect of lactic acid as the capping agent during the formation of $\mathrm{FeOOH}$ nanoparticles was clearly evaluated based on the transmission electron microscopic images (TEM). Fig. 5.A showed the TEM image of FeOOH nanoparticles during heating the $\mathrm{Fe}^{3+}\left(0.01 \mathrm{~mol} \mathrm{~L}^{-1}\right)$ solution, whereas Fig. 5.B was related to the formation of $\mathrm{FeOOH}$ during using lactic acid standard solution $\left(1.0 \mathrm{mmol} \mathrm{L}^{-1}\right)$ in the presence of $\mathrm{Fe}^{3+}$ standard solution $\left(0.01 \mathrm{~mol} \mathrm{~L}^{-1}\right)$. Partial difference between the sizes of the $\mathrm{FeOOH}$ nanoparticles was probably related to the different matrices of the samples.

\section{Equation}

$6 \mathrm{FeOOH}+\mathrm{CO} \quad 2 \mathrm{Fe}_{3} \mathrm{O}_{4}+\mathrm{CO}+3 \mathrm{H}_{2} \mathrm{O} \quad$ Eq. 2

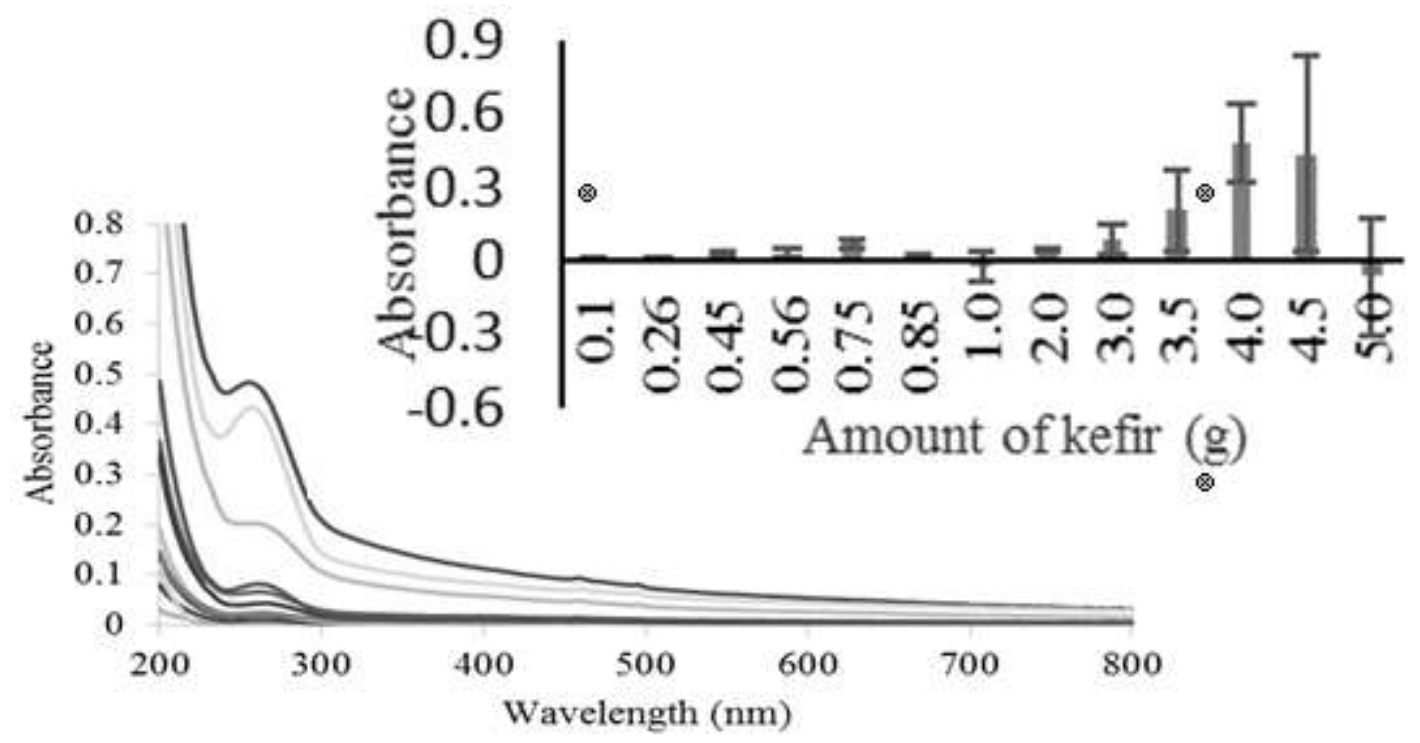

Figure 1:- Optimum amount of kefir grains (during contacting kefir suspension with lactose standard solution (0.1 $\mathrm{mmol} \mathrm{L}{ }^{-1}, \mathrm{n}=3$ ). Inset) histogram.

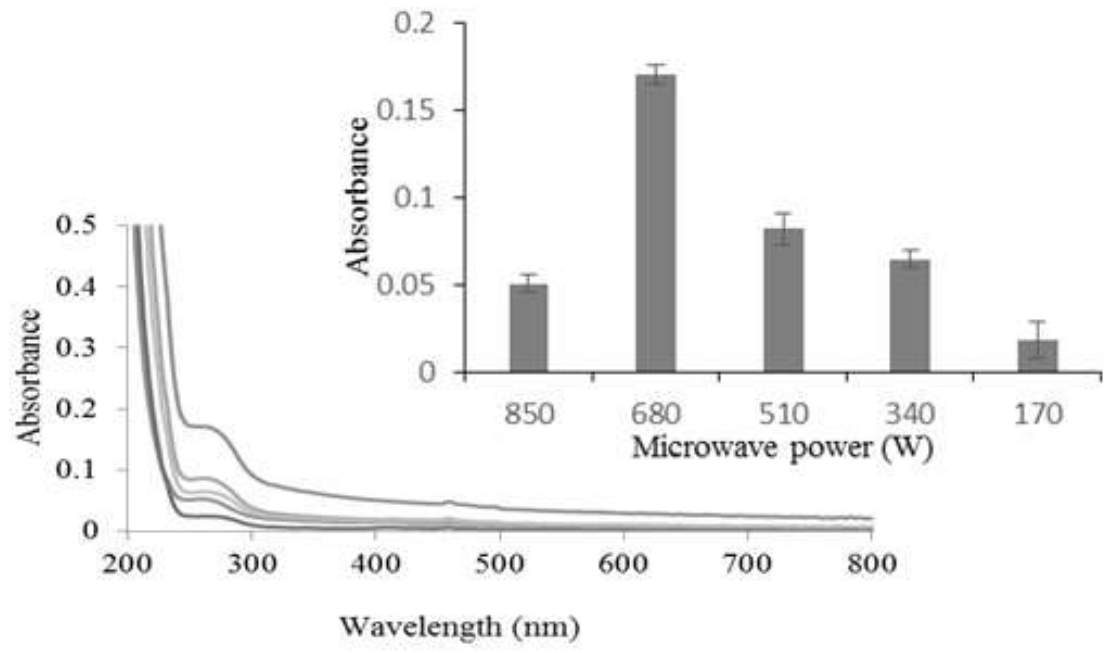

Figure 2:- Effect of microwave radiation on the absorbance sensi-tivity of $0.1 \mathrm{mmol} \mathrm{L}^{-1}$ lactose standard solution. Inset) histogram. 


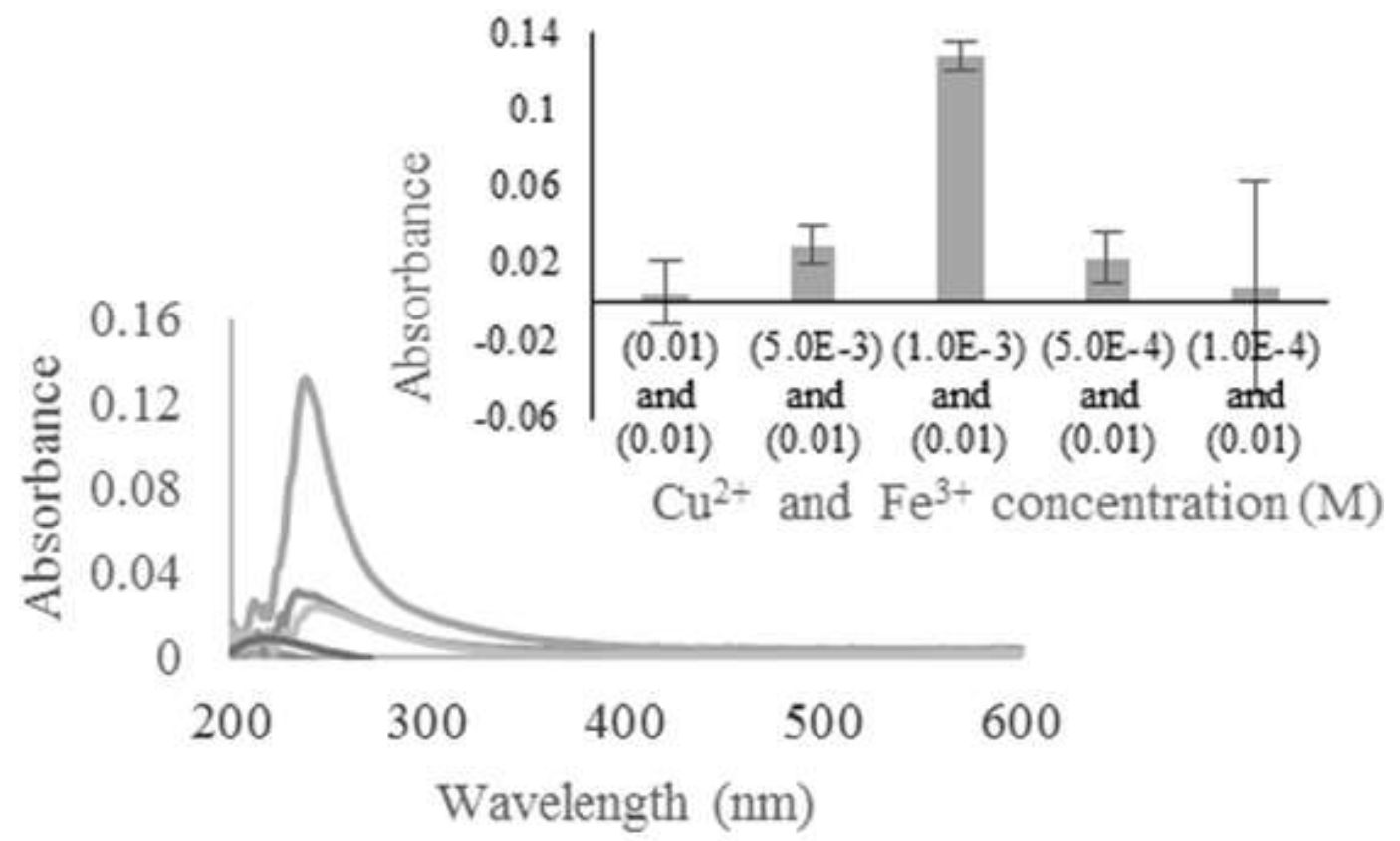

Figure 3:- Optimum concentrations of $\mathrm{Fe}^{3+}$ and $\mathrm{Cu}^{2+}$ species during analysis of lactose $\left(0.1 \mathrm{mmol} \mathrm{L}^{-1}\right)$ in the sample solutions at the optimized condition ( $\mathrm{n}=3$ ). Inset) histogram.
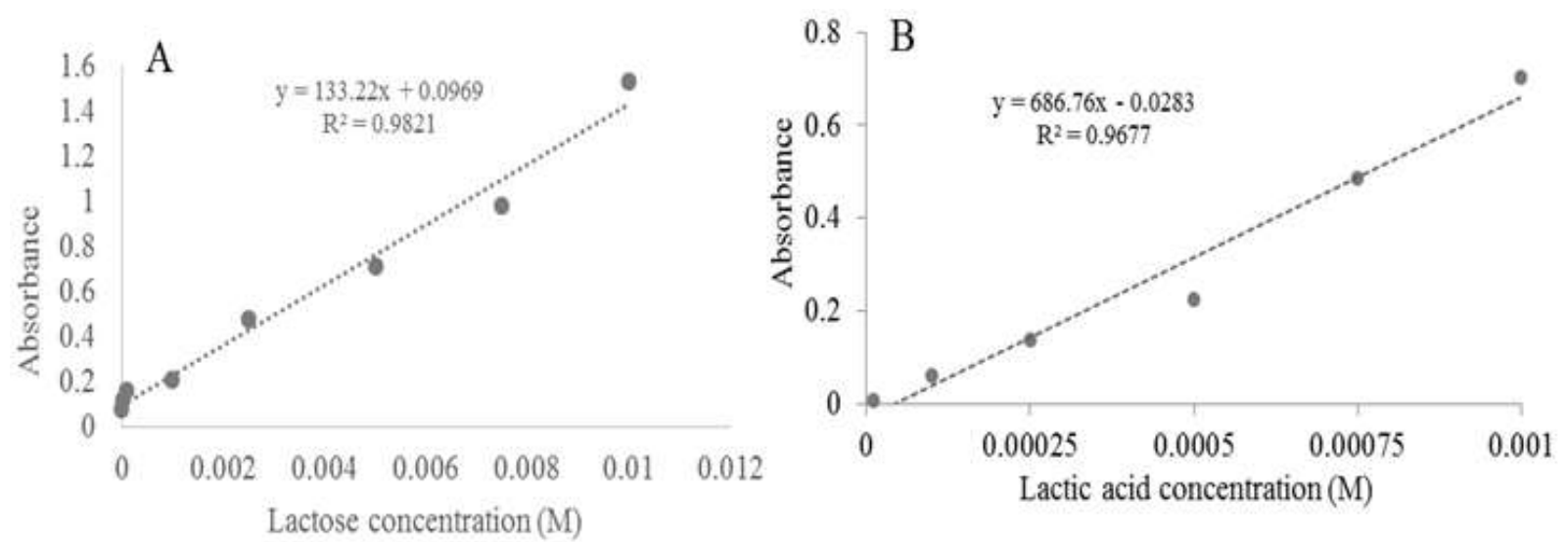

Figure 4:- A) Lactose calibration curve B) Lactic acid calibration curves.
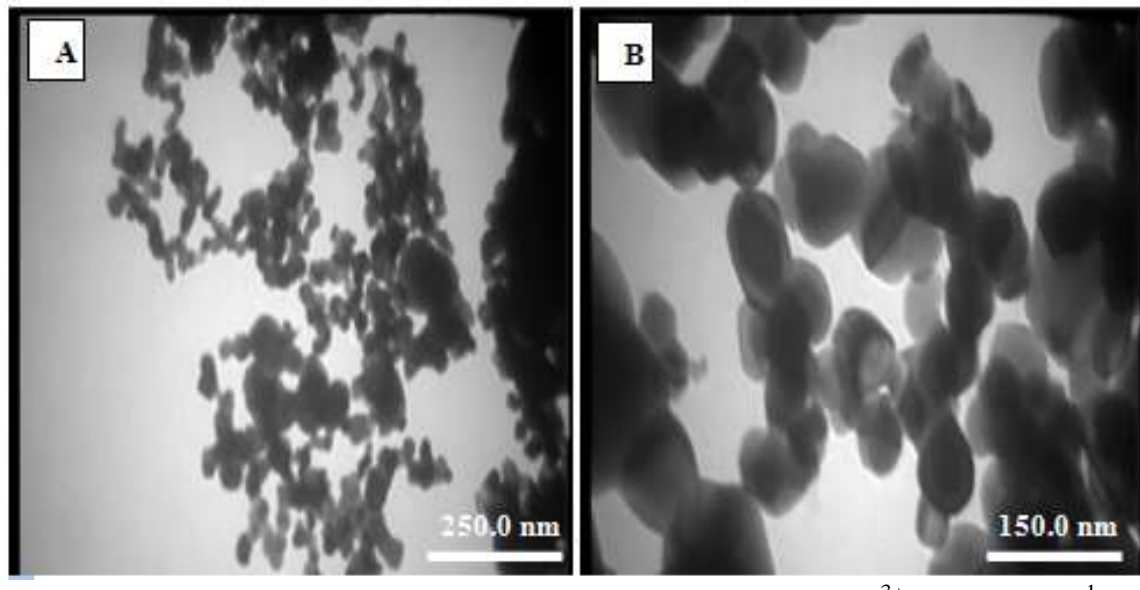

Figure 5:- TEM image of $\mathrm{FeOOH}$ nanoparticles during $\mathrm{A})$ heating the $\mathrm{Fe}^{3+}\left(0.01 \mathrm{~mol} \mathrm{~L}^{-1}\right)$ solution $\left.\mathrm{B}\right)$ during using lactic acid standard solution $\left(1.0 \mathrm{mmol} \mathrm{L}^{-1}\right)$ in the presence of $\mathrm{Fe}^{3+}$ standard solution $\left(0.01 \mathrm{~mol} \mathrm{~L}^{-1}\right)$. 
Graphical Abstract

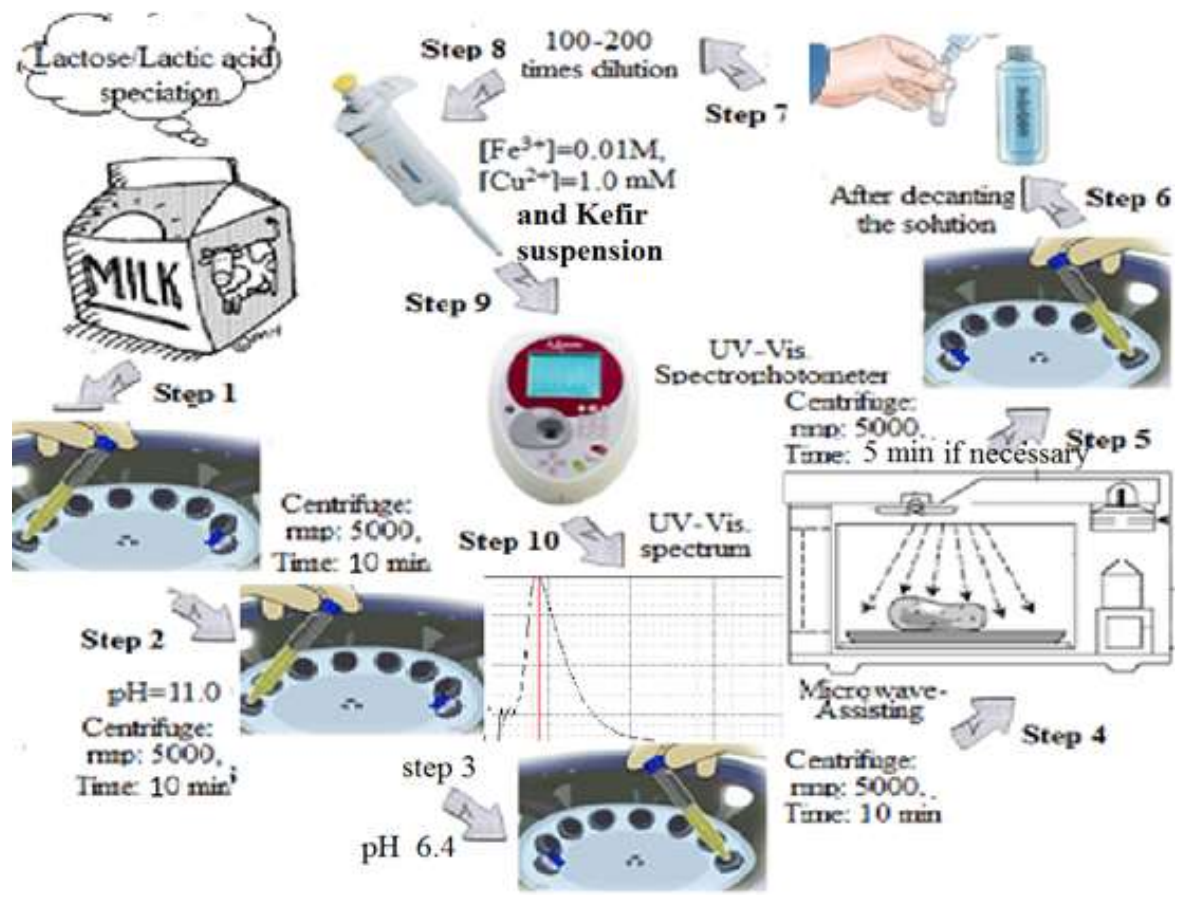

\section{Supporting Information}

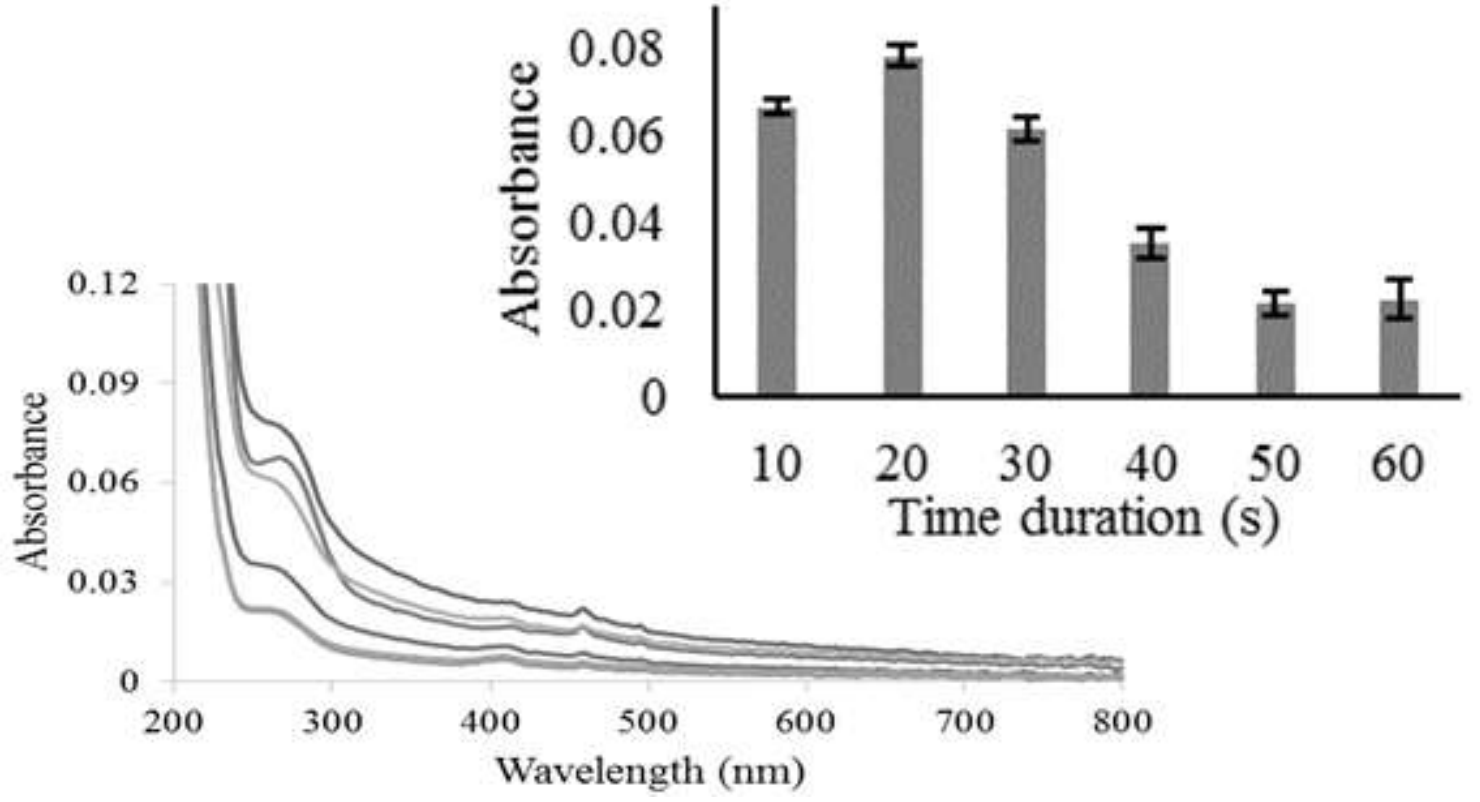

Figure 1.SP. Effect of time duration of microwave radiation on the absorbance sensitivity of lactose standard solution $\left(0.1 \mathrm{mmol} \mathrm{L}^{-1}\right)$ at the optimized condition $(\mathrm{n}=3)$. Inset $)$ histogram. 


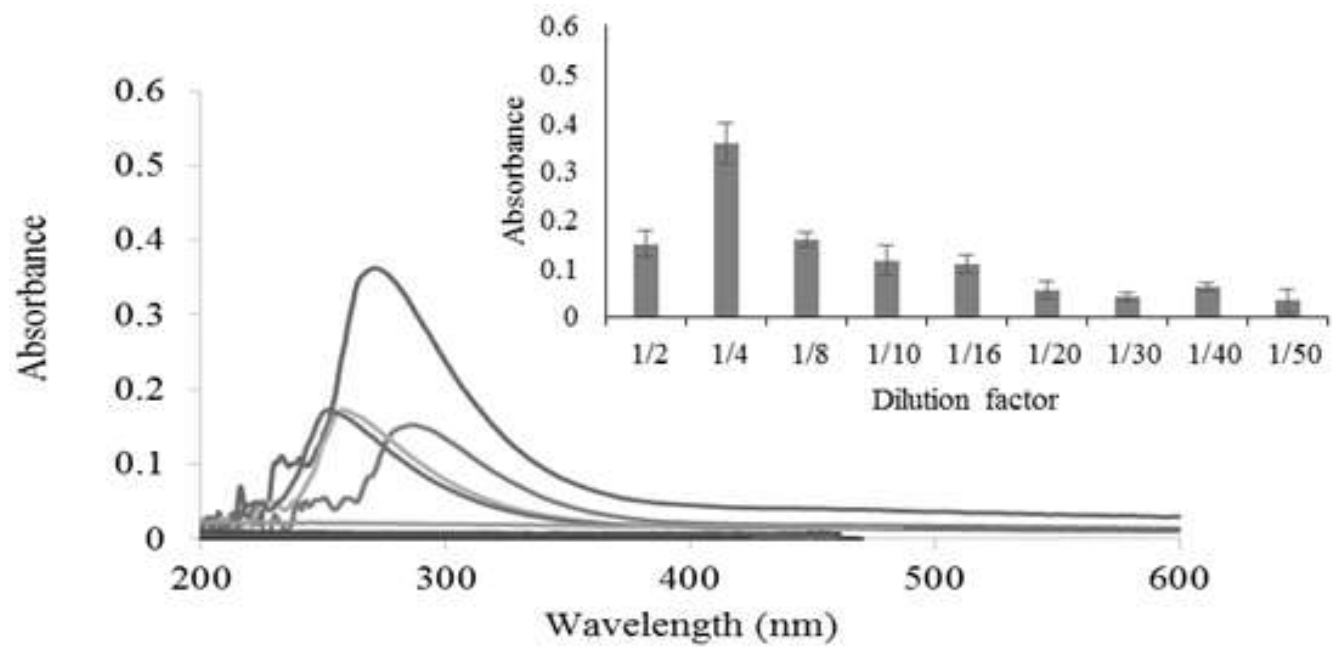

Figure 2.SP:- Effect of dilution of blank solution on the absorbance sensitivity of lactose standard solution (0.1 mmol L $\left.{ }^{-1}\right)$ and kefir grains suspension in the sample solution $(n=3)$ Inset) histogram.

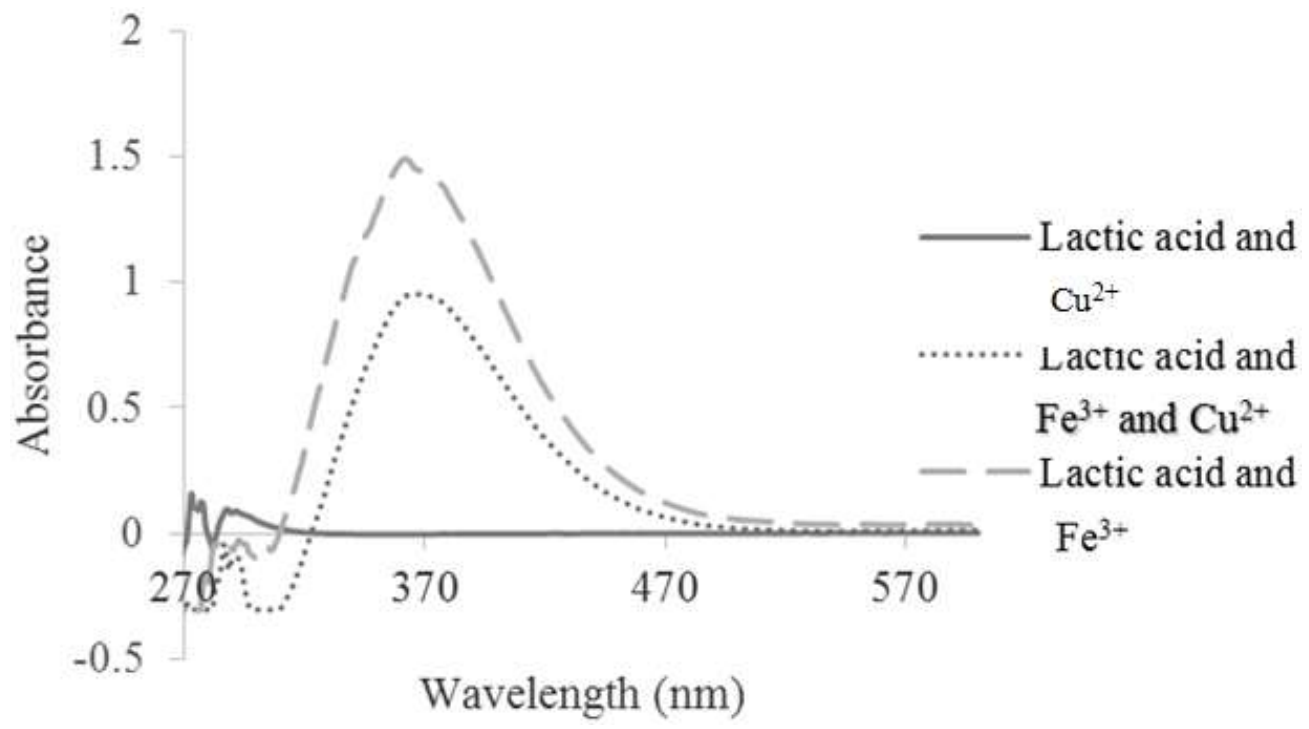

Figure 3.SP:- Effect of $\mathrm{Fe}^{3+}\left(1.0 \mathrm{mmol} \mathrm{L}^{-1}\right)$ and $\mathrm{Cu}^{2+}\left(1.0 \mathrm{mmol} \mathrm{L}^{-1}\right)$ during $\mathrm{UV}-\mathrm{Vis}$. analyses of lactic acid standard solution $\left(0.01 \mathrm{~mol} \mathrm{~L}^{-1}\right)$ in the sample solutions.

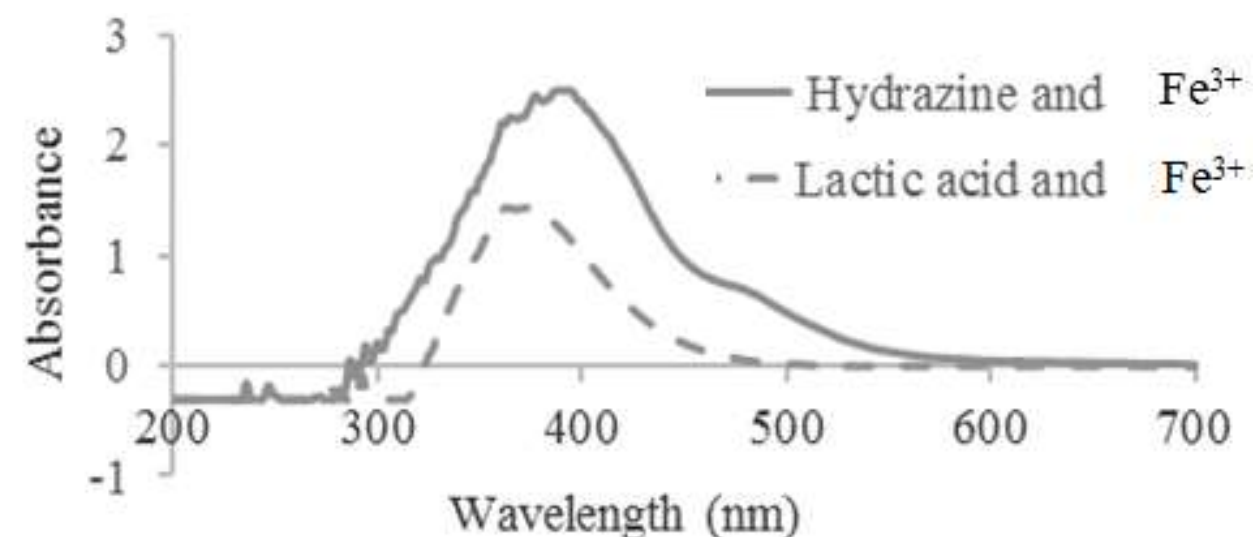

Figure 4.SP:- Comparison between the UV-Vis spectra of FeOOH generated in the presence of lactic acid (0.01 mol $\left.\mathrm{L}^{-1}\right)$ and $\mathrm{Fe}^{3+}\left(0.01 \mathrm{~mol} \mathrm{~L}^{-1}\right)$ with that synthesized in literature. 


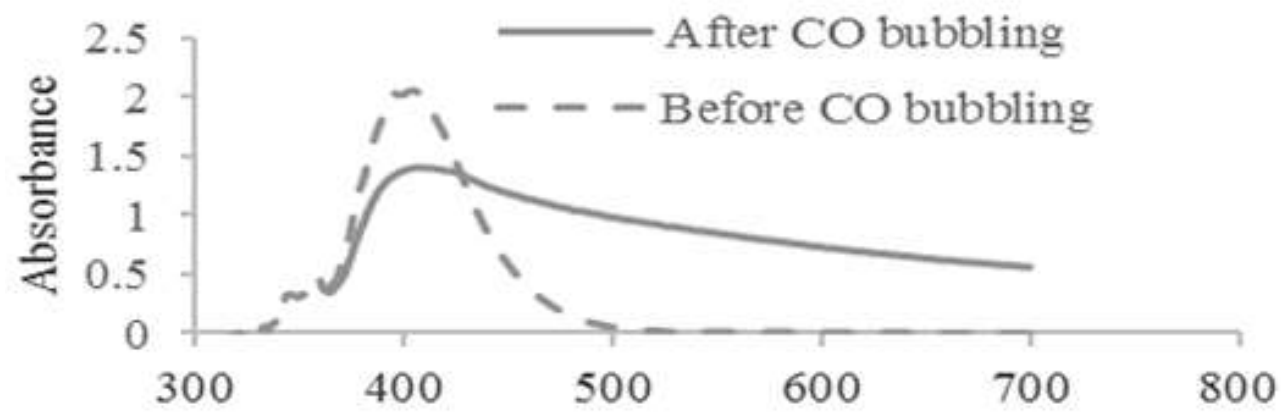

\section{Wavelength ( $\mathrm{nm}$ )}

Figure 5.SP. Effect of $\mathrm{CO}$ on formation of $\mathrm{Fe}_{3} \mathrm{O}_{4}$ generated from $\mathrm{FeOOH}$ in the presence of lactic acid $(0.01 \mathrm{M})$ and $\mathrm{Fe}^{3+}\left(0.01 \mathrm{~mol} \mathrm{~L}^{-1}\right)$.

\section{Conclusions:-}

A sensitive and selective method has been introduced for lactose and lactic acid determination. This technique has some beneficial aspects such as more simplicity, selectivity, fast response time and acceptable detection limit. More acceptable response time and detection limit was estimated for each lactose and lactic acid, compared to the general methods such as titrimetry, high-performance liquid chromatography and infrared spectrometry. This study points to the dangerous effect of the formation of $\mathrm{FeOOH}$ nanoparticles during the use of Kefir in our nutrient chain based on the catalytic effect of the kefir's microorganism and ion species and copping behavior of lactic acid.

\section{Acknowledgment:-}

The authors wish to acknowledge the support of this work by the Shiraz University Research Council.

\section{References:-}

1. Abdel-Rahman, M. A., Tashiro, Y., \& Sonomoto, K. (2011). Zeitschrift für Lebensmitteluntersuchung und Forschung. Journal of Biotechnology, 156, 286-301.

2. Andersson, R., \& Hedlund, B. (1983). HPLC analysis of organic acids in lactic acid fermented vegetables. Zeitschrift für Lebensmittel-Untersuchung und Forschung, 176, 440-443.

3. Andrei, S. Veterinary Medicine, Bulletin of University of Agricultural Sciences and Veterinary Medicine ClujNapoca, 2008. URL http://journals.usamvcluj.ro/index.php/veterinary

4. Atasever, A., Ozdemir, H., Gulcin, I., \& Irfan Kufrevioglu, O. (2013). One-step purification of lactoperoxidase from bovine milk by affinity chromatography. Food Chemistry, 136(2), 864-870.

5. Cross, K. J., Huq, N. L., Palamara, J. E., Perich, J. W., \& Reynolds, E. C. (2005). Physicochemical characterization of casein phosphopeptide-amorphous calcium phosphate nanocomplexes. Journal of Biological Chemistry, 280 , 15362-15369.

6. Deng, D., Cheng, Y., Jin, Y., Qi, T., \& Xiao, F. (2012). Antioxidative effect of lactic acid-stabilized copper nanoparticles prepared in aqueous solution. Journal of Materials Chemistry, 22, 23989-23995.

7. Enikeev, R. (2012). Development of a new method for determination of exopolysaccharide quantity in fermented milk products and its application in technology of kefir production. Food Chemistry, 134(4), 2437-2441.

8. Fontán, M. C. G., Martínez, S., Franco, I., \& Carballo, J. (2006). Microbiological and chemical changes during the manufacture of Kefir made from cows' milk, using a commercial starter culture. International Dairy Journal, 16(7), $762-767$.

9. Gao, J., Gu, F., Ruan, H., Chen, Q., He, J., \& He, G. (2012). Culture conditions optimization of tibetan kefir grains by response surface methodology. Procedia Engineering, 37, 132-136.

10. Garofalo, C., Osimani, A., Milanović, V., Aquilanti, L., De Filippis, F., Stellato, G., Di Mauro, S., Turchetti, B., Buzzini, P., \& Ercolini, D. (2015). Bacteria and yeast microbiota in milk kefir grains from different Italian regions. Food Microbiology, 49, 123-133.

11. Genin, E., Toullec, P. Y., Antoniotti, S., Brancour, C., Genet, J. P., \& Michelet, V. (2006). Room temperature Au(I)catalyzed exo-selective cycloisomerization of acetylenic acids: an entry to functionalized gamma-lactones. Journal of the American Chemical Society, 128(10), 3112-3113. 
12. Goncu, A., \& Alpkent, Z. (2005). Sensory and chemical properties of white pickled cheese produced using kefir, yoghurt or a commercial cheese culture as a starter. International Dairy Journal, 15, 771-776.

13. Halliwell, B., \& Gutteridge, J. M. (1985). The importance of free radicals and catalytic metal ions in human diseases. Molecular Aspects of Medicine, 8, 89-193.

14. Heinemann, M., \& Hald, P. M. (1940). Factors That Influence the Passage of Ascorbic Acid from Serum to Cells in Human Blood. Journal of Clinical Investigation, 19(3), 469-473.

15. Hertzler, S. R., \& Clancy, S. M. (2003). Kefir improves lactose digestion and tolerance in adults with lactose maldigestion. Journal of the American Dietetic Association, 103, 582-587.

16. Horne, D. S. (2006). Casein micelle structure: models and muddles. Current Opinion in Colloid \& Interface Science, $11,148-153$.

17. Ilmen, M., Koivuranta, K., Ruohonen, L., Suominen, P., \& Penttila, M. (2007). Efficient production of L-lactic acid from xylose by Pichia stipitis. Applied and Environmental Microbiology, 73(1), 117-123.

18. Jamshidi, K., Hyon, S.-H., \& Ikada, Y. (1988). Thermal characterization of polylactides. Polymer, 29, $2229-2234$.

19. Klopper, W., Angelino, S., Tuning, B., \& Vermeire, H. (1986). Organic acids and glycerol in beer. Journal of the Institute of Brewing, 92, 225-228.

20. Lane, J. H., \& Eynon, L. (1934). Determination of reducing sugars by Fehling's solution with methylene blue indicator. London: N. Rodger.

21. Luinge, H., Hop, E., Lutz, E., Van Hemert, J., \& De Jong, E. (1993). Determination of the fat, protein and lactose content of milk using Fourier transform infrared spectrometry. Analytica Chimica Acta, 284, 419-433.

22. McMahon, D. J., \& McManus, W. R. (1998). Rethinking casein micelle structure using electron microscopy. Journal of Dairy Science, 81, 2985-2993.

23. Ni, Y. N., Wang, Y. R., \& Kokot, S. (2008). Osteryoung square wave voltammetric determination of lactose in food samples by a derivative procedure. Chinese Chemical Letters, 19, 1491-1494.

24. Nickerson, T., Vujicic, I., \& Lin, A. (1976). Colorimetric estimation of lactose and its hydrolytic products. Journal of Dairy Science, 59, 386-390.

25. Pfennig, B. W. (2015). Principles of Inorganic Chemistry. United Kingdom: John Wiley \& Sons.

26. Qiao, R., Yang, C., \& Gao, M. (2009). Superparamagnetic iron oxide nanoparticles: from preparations to in vivo MRI applications. Journal of Materials Chemistry, 19, 6274-6293.

27. RedCorn, R., \& Engelberth, A. S. (2016). Identifying conditions to optimize lactic acid production from food waste co-digested with primary sludge. Biochemical Engineering Journal, 105, 205-213.

28. Rimstidt, J. D. (2013). Geochemical rate models: an introduction to geochemical kinetics. New York: Cambridge University Press.

29. Riva, A., \& Bisognani, M. (1972). Infrared spectrophotometric determination of small amounts of lactic and pyruvic acids. Analytical chemistry, 44, 2101-2101.

30. Safina, Z. M., Abizgil'dina, G., Gabdrakhmanova, A. F., \& Safina, E. R. (2010). Effectiveness of infrared exposure to periorbital areas in partial optic nerve atrophy of varying degrees. Vestnik Oftalmologii, 126(5), 31-34.

31. Schlimme, E., Lorenzen, P. C., Martin, D., \& Thormahlen, K. (1996). Analytical differentiation of butter types by specific compositional parameters of the aqueous butter phase. Milchwissenschaft, 51, 139-143.

32. Serafini, F., Turroni, F., Ruas-Madiedo, P., Lugli, G. A., Milani, C., Duranti, S., Zamboni, N., Bottacini, F., van Sinderen, D., \& Margolles, A. (2014). Kefir fermented milk and kefiran promote growth of Bifidobacterium bifidum PRL2010 and modulate its gene expression. International Journal of Food Microbiology, 178, 50-59.

33. Simova, E., Beshkova, D., Angelov, A., Hristozova, T., Frengova, G., \& Spasov, Z. (2002). Lactic acid bacteria and yeasts in kefir grains and kefir made from them. Journal of Industrial Microbiology \& Biotechnology, 28(1), 1-6.

34. Swagerty Jr, D. L., Walling, A. D., \& Klein, R. M. (2002). Lactose intolerance. American family physician, 65, 18451850 .

35. Tango, T. (1999). Re: Improved confidence intervals for the difference between binomial proportions based on paired data by Robert G. Newcombe. Statistics in Medicine, 17, 2635-2650.

36. Xinmin, W., Ruili, Z., Zhihua, L., Yuanhong, W., \& Tingfu, J. (2008). Determination of glucosamine and lactose in milk-based formulae by high-performance liquid chromatography. Journal of food composition and analysis, 21, 255258.

37. Yakovleva, M., Buzas, O., Matsumura, H., Samejima, M., Igarashi, K., Larsson, P.-O., Gorton, L., \& Danielsson, B. (2012). A novel combined thermometric and amperometric biosensor for lactose determination based on immobilised cellobiose dehydrogenase. Biosensors and Bioelectronics, 31, 251-256. 